\title{
A randomized controlled trial of fall prevention by a high-intensity functional exercise program for older people living in residential care facilities
}

\author{
Erik Rosendahl1,2, Yngve Gustafson ${ }^{1}$, Ellinor Nordin'1, Lillemor Lundin-Olsson' ${ }^{1}$, and Lars Nyberg ${ }^{2}$ \\ 1Department of Community Medicine and Rehabilitation, Geriatric Medicine and Physiotherapy, Umeå \\ University, Umeå, 2Department of Health Sciences, Physiotherapy Unit, Luleå University of Technology, \\ Luleå, Sweden
}

ABSTRACT. Background and aims: Falls are particularly common among older people living in residential care facilities. The aim of this randomized controlled trial was to evaluate the effectiveness of a high-intensity functional exercise program in reducing falls in residential care facilities. Methods: Participants comprised 191 older people, 139 women and 52 men, who were dependent in activities of daily living. Their mean $\pm S D$ score on the Mini-Mental State Examination was 17.8 \pm 5.1 (range 10-30). Participants were randomized to a high-intensity functional exercise program or a control activity, consisting of 29 sessions over 3 months. The fall rate and proportion of participants sustaining a fall were the outcome measures, subsequently analysed using negative binominal analysis and logistic regression analysis, respectively. Results: During the 6-month follow-up period, when all participants were compared, no statistically significant differences between groups were found for fall rate (exercise group 3.6 falls per person years [PY], control group 4.6 falls per $P Y)$, incidence rate ratio (95\% CI) 0.82 (0.49-1.39), $\mathrm{p}=0.46$, or the proportion of participants sustaining a fall (exercise $53 \%$, control $51 \%)$, odds ratio (95\% CI) 0.95 (0.52-1.74), $\mathrm{p}=0.86$. A subgroup interaction analysis revealed that, among participants who improved their balance during the intervention period, the exercise group had a lower fall rate than the control group (exercise 2.7 falls per PY, control 5.9 falls per $P Y)$, incidence rate ratio (95\% CI) 0.44 (0.21-0.91), $p=0.03$. Conclusions: In older people living in residential care facilities, a high-intensity functional exercise program may prevent falls among those who improve their balance.

(Aging Clin Exp Res 2008; 20: 67-75)

(92008, Editrice Kurtis

\section{INTRODUCTION}

Falls are common among older people and pose a major threat to health and independence. Among people aged 65 years and over, one-third of those living in the community (i.e., in their own homes) fall each year (1-3), almost half of the accidents result in an injury $(3,4)$, and around one in twenty in a fracture $(1,3)$. In older people, falls are the leading cause of death from injury (5). The psychological consequences of falls are also common, and one-third of older people who sustain a fall are worried about falling again (6). Fear of falling leads to an increased risk of inactivity and a reduction in the ability to perform activities of daily living, as well as to an increased risk of falling $(7,8)$. Among older people living in residential care facilities, almost two-thirds fall each year (9) and they experience falls three times more frequently than older people living in the community (2). In addition, the incidence rates for both fall-related major soft tissue injuries and fractures are more than twice as high for this group of older people (10).

A large number of risk factors have been identified in the literature, illustrating the complex causality of falls. Impairment regarding balance, gait, muscle strength, vision, or cognition, as well as medical conditions, drug use, and environmental hazards are frequently reported as important risk factors $(11,12)$. There is currently strong evidence that multifactorial intervention programs, based on individual screening for risk factors, have a preventive potential among older people living in the community (13, 14). Among older people living in residential care facilities, evidence of the effectiveness of multifactorial interventions programs is weaker, since contradictory results have been reported (15-21). However, two studies concerning multifactorial interventions have been successful in re-

Key words: Accidental falls/prevention and control, aged, exercise, frail elderly, randomized controlled trials, residential facilities.

Correspondence: Erik Rosendahl, PhD, Department of Health Sciences, Physiotherapy Unit, Luleå University of Technology, SE-971 87 Luleå, Sweden.

E-mail: erik.rosendahl@ltu.se

Received May 8, 2006; accepted in revised form January 24, 2007. 
ducing falls $(16,19)$. In both these studies, high-intensity strength and balance exercises formed part of the fall prevention program.

When designing an exercise program with a view to preventing falls, it is important to try to improve lower-limb strength, balance and gait ability (12). The intensity of the exercise is also an important aspect, since high-intensity exercise (i.e., training near the individual's maximum capacity) has a greater effect on physical functions than low-intensity exercise (22). Exercise programs have proved to be an important part of multifactorial preventive interventions $(13,23)$ and have also been effective as single interventions in older people, both those living in the community (24-27) and in retirement villages (28). It seems important, in achieving a fall prevention effect, that the exercises should be individually tailored, target both strength and balance, and mainly performed in weight-bearing positions. Among residents in nursing homes and other residential care facilities, various exercise interventions which failed to show significant effects on balance and strength have not succeeded in preventing falls $(29,30)$. One controlled study using computerised high-intensity dynamic balance training, which led to an improvement in functional balance (31), was successful in reducing falls. However, as stated by the author, the sample size was small $(\mathrm{n}=27)$, which limits the external validity of the results (32). Thus, in older people living in residential care facilities, there is a lack of knowledge about the fall-prevention effect of a high-intensity exercise program that targets strength and balance and is successful in improving these risk factors for falls. It is important to evaluate this, even though two multifactorial studies which included high-intensity exercise have already been successful in reducing falls in residential care facilities, since the fall-preventive effect of the exercise could not be evaluated from these studies. In addition, an exercise program successful as a single intervention demands fewer resources to administer than a multifactorial intervention.

We have recently reported on improved balance, lower-limb strength and gait performance as a result of a highintensity functional exercise program for older people, dependent in activities of daily living (ADL) and living in residential care facilities, compared with a control activity (33). We hypothesized that this exercise program would also result in a reduction in falls during the six months following the intervention.

\section{METHODS}

\section{Setting}

This study was carried out in nine residential care facilities in Umeå, Sweden. All facilities comprised private apartments with access to dining facilities, alarms, and on-site nursing and care. Four facilities also comprised units with private rooms and staff on hand, for people with dementia.

\section{Participants}

Inclusion criteria were: aged 65 or over, dependent on assistance from a person in one or more personal ADL according to the Katz Index (34), able to stand up from a chair with armrests with help from no more than one person, a Mini-Mental State Examination (MMSE) (35) score of ten or more, and approval from the resident's physician.

All residents $(n=487)$ were screened by trained physiotherapists (PTs) during the first two months of 2002. Residents who met the inclusion criteria, or their relatives when appropriate due to cognitive impairment, gave their informed oral consent to participation. One hundred and ninety-one people, aged 65-100 years, were included (Fig. 1). Age $(p=0.84)$, sex $(p=0.64)$, and Katz ADL Index score $(p=0.66)$ did not differ between those who were included and those who refused to participate. The study was approved by the Ethics Committee of the Medical Faculty of Umeå University (§391/01).

\section{Study design}

The study was a part of the Frail Older People - Activity and Nutrition Study in Umeå (the FOPANU Study), a stratified-cluster, randomized, controlled trial comprising both an exercise intervention compared with a control activity and a nutrition intervention compared with placebo in a $2 \times 2$ factorial model (33). Only the exercise intervention was evaluated in the present fall prevention study, as the nutrition intervention had no effect on physical function. The exercise intervention and control activity were presented to participants and staff at the facilities without indication of the study hypothesis.

\section{Randomization}

Randomization was performed after inclusion of participants and baseline assessments. To reduce contamination by the exercise intervention, 34 clusters, comprising 3 to 9 participants living on the same floor, wing or unit, were randomly assigned to the exercise group or the control group. Randomization was stratified in order to have both groups in each facility, to minimize the risk of impact from factors associated with the facility. Researchers not involved in the study performed randomization by using lots in sealed non-transparent envelopes.

\section{Exercise intervention}

The exercise intervention, based on the High-Intensity Functional Exercise Program (HIFE Program), is described in detail elsewhere (36). The aim of the intervention was to improve participants' lower-limb strength, balance and gait ability. The PTs selected exercises for each participant according to their functional deficits. All exercises were performed in weight-bearing positions - for example, squats, turning the trunk and head 


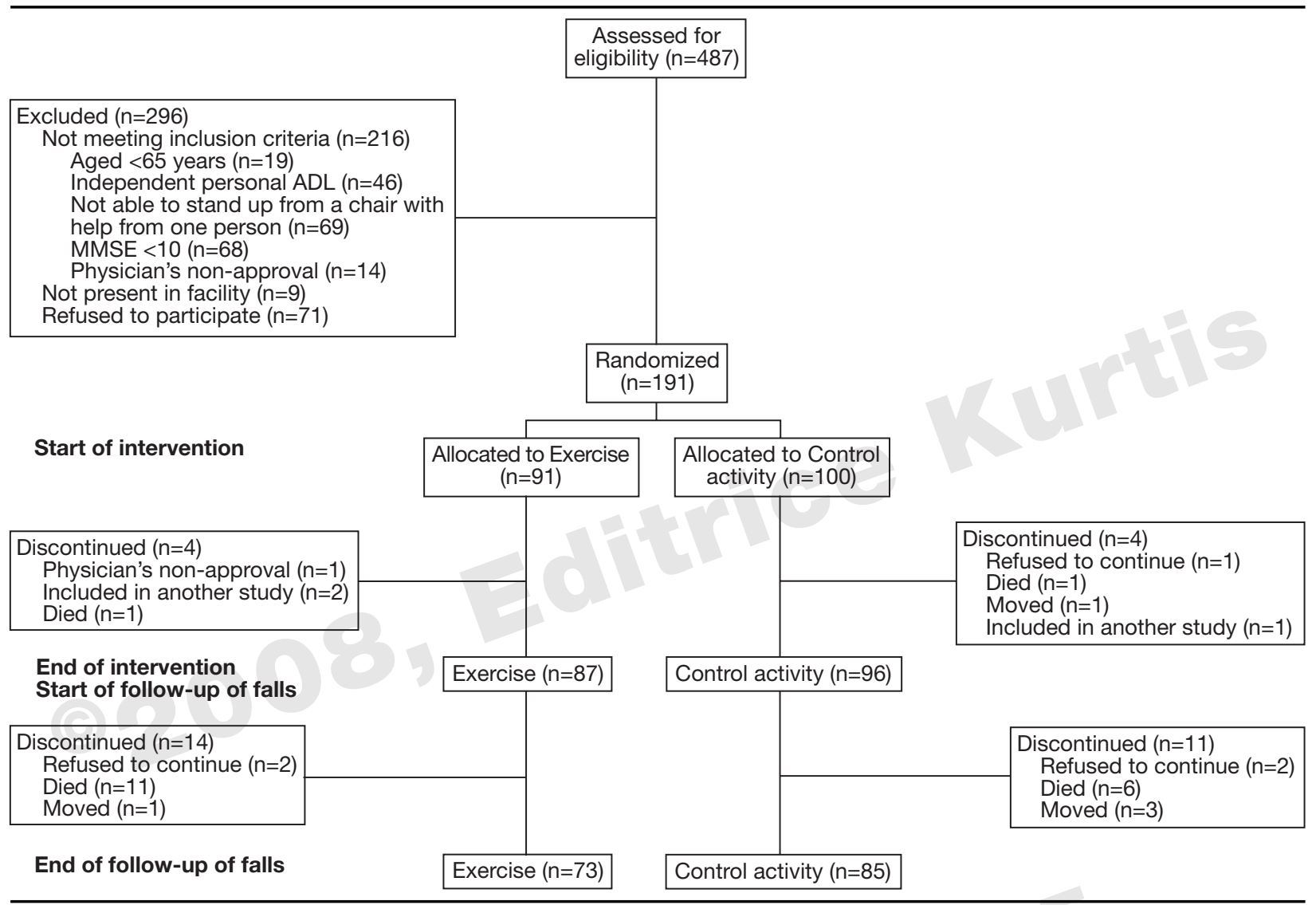

Fig. 1 - Flow of participants through the trial.

while standing, and walking over obstacles. Participants were encouraged by the PTs to exercise at high intensity and to increase load and difficulty progressively, taking into consideration changes in functional and health status. Strength exercises were intended to be performed at 8-12 repetition maximum (RM) (37). The load in the strength exercises was progressively increased by adjusting the performance of the exercise by, for example, doing deeper squats or step-ups on to a higher box, or by using a weighted belt worn around the waist, loaded with a maximum of $12 \mathrm{~kg}$. Balance exercises were intended to challenge the participant's postural stability fully. The difficulty of each balance exercise was progressively increased - for example, by standing or walking with a narrower base of support, or on a more challenging surface. At the end of the exercise period, physical tasks were introduced for the participant, in cooperation with a staff member, in order to maintain physical function. The tasks were to be integrated into daily activities and were individually recommended regarding type (e.g., walking, squats, standing without balance support), number (one to four) and frequency (weekly, up to daily).

\section{Control activity}

The control activity program was developed for this study by occupational therapists (OT) and included activities performed while sitting, e.g., watching films, reading, singing, and conversation. The program was based on themes, e.g., the old country shop, famous people, and games from the past, and was expected to be interesting and stimulating for older people including those with severe cognitive impairment.

\section{Procedure of exercise intervention and control activity}

The exercise intervention and control activity started in March 2002, and were performed in groups of 3-9 participants supervised by two PTs (exercise) or one OT (control). Each session lasted approximately 45 minutes and was held five times every two weeks for 3 months (13 weeks), for a total of 29 occasions. When a participant did not attend the group session, individual activity was offered if possible. Attendance was $72 \%$ for the exercise group and $70 \%$ for the control group (33). Six percent of the sessions were performed individually (the same in both groups). 


\section{Outcome}

The fall rate and the proportion of participants sustaining a fall were the outcome measures in evaluating the fall-prevention effect of the exercise program. The followup period was planned to last six months from the end of the intervention. Participants' absence from the facility was

Table 1 - Baseline characteristics of participants.

\begin{tabular}{|c|c|c|c|c|}
\hline Characteristics & Total $n=191$ & Exercise $\mathbf{n}=91$ & Control $n=100$ & $\boldsymbol{p}$ \\
\hline Age, mean $\pm \mathrm{SD}$ (range) & $\begin{array}{l}84.7 \pm 6.5 \\
(65-100)\end{array}$ & $\begin{array}{l}85.3 \pm 6.1 \\
(68-100)\end{array}$ & $\begin{array}{c}84.2 \pm 6.8 \\
(65-98)\end{array}$ & 0.28 \\
\hline Female sex, $\mathrm{n}(\%)$ & $139(73)$ & $67(74)$ & $72(72)$ & 0.80 \\
\hline Previous falls, last 6 months $(n=174)$ & $75(43)$ & $36(44)$ & $39(42)$ & 0.74 \\
\hline \multicolumn{5}{|l|}{ Diagnoses and medical conditions, $n(\%)$} \\
\hline Depression & $116(61)$ & $55(60)$ & $61(61)$ & 0.94 \\
\hline Dementia & $100(52)$ & $47(52)$ & $53(53)$ & 0.85 \\
\hline Delirium episodes in last month & $50(26)$ & $21(23)$ & $29(29)$ & 0.35 \\
\hline Previous stroke & $54(28)$ & $26(29)$ & $28(28)$ & 0.93 \\
\hline Diabetes mellitus & 37 (19) & $14(15)$ & $23(23)$ & 0.18 \\
\hline Heart failure & $52(27)$ & $25(28)$ & $27(27)$ & 0.94 \\
\hline Angina pectoris & $53(28)$ & $27(30)$ & $26(26)$ & 0.57 \\
\hline Fracture in last five years & $66(35)$ & $31(34)$ & $35(35)$ & 0.89 \\
\hline Malignancy in last five years & $24(13)$ & $10(11)$ & $14(14)$ & 0.53 \\
\hline \multicolumn{5}{|l|}{ Drugs for regular use, $n(\%)$} \\
\hline Diuretics & $94(49)$ & $45(50)$ & $49(49)$ & 0.95 \\
\hline Analgesics & $111(58)$ & $56(62)$ & $55(55)$ & 0.36 \\
\hline Benzodiazepines & $76(40)$ & $35(38)$ & $41(41)$ & 0.72 \\
\hline Antidepressants & $94(49)$ & $46(50)$ & $48(48)$ & 0.72 \\
\hline Neuroleptics & $42(22)$ & $17(19)$ & $25(25)$ & 0.29 \\
\hline Oestrogen & $56(29)$ & $23(25)$ & $33(33)$ & 0.24 \\
\hline Laxatives & $102(53)$ & $46(50)$ & $56(56)$ & 0.45 \\
\hline Calcium and vitamin D & $38(20)$ & $18(20)$ & $20(20)$ & 0.97 \\
\hline Number of drugs, mean \pm SD (range) & $\begin{array}{c}9.1 \pm 4.4 \\
(0-27)\end{array}$ & $\begin{array}{c}9.2 \pm 5.0 \\
(1-27)\end{array}$ & $\begin{array}{c}9.0 \pm 3.9 \\
(0-18)\end{array}$ & 0.74 \\
\hline \multicolumn{5}{|l|}{ Functional assessments } \\
\hline Visual impairment, $\mathrm{n}(\%)$ & $56(29)$ & $32(35)$ & $24(24)$ & 0.09 \\
\hline Hearing impairment, $\mathrm{n}(\%)$ & $46(24)$ & $24(26)$ & $22(22)$ & 0.48 \\
\hline Mini Mental State Examination (0-30), mean \pm SD (range) & $\begin{array}{c}17.8 \pm 5.1 \\
(10-30)\end{array}$ & $\begin{array}{c}17.5 \pm 5.0 \\
(10-29)\end{array}$ & $\begin{array}{c}18.0 \pm 5.3 \\
(10-30)\end{array}$ & 0.54 \\
\hline Barthel ADL Index (0-20), mean \pm SD (range) & $\begin{array}{c}13.1 \pm 4.2 \\
(1-19)\end{array}$ & $\begin{array}{c}12.8 \pm 4.5 \\
(1-19)\end{array}$ & $\begin{array}{c}13.4 \pm 3.8 \\
(4-19)\end{array}$ & 0.32 \\
\hline Independent gait indoors (with or without walking aid)*, n (\%) & $121(63)$ & $56(62)$ & $65(65)$ & 0.62 \\
\hline Gait speed, self-paced m/s, mean \pm SD (range) $(n=166)$ & $\begin{array}{c}0.40 \pm 0.16 \\
(0.05-1.00)\end{array}$ & $\begin{array}{l}0.39 \pm 0.16 \\
(0.05-0.94)\end{array}$ & $\begin{array}{l}0.41 \pm 0.16 \\
(0.05-1.00)\end{array}$ & 0.87 \\
\hline Berg Balance Scale (0-56), mean \pm SD (range) $(n=190)$ & $\begin{array}{c}26.6 \pm 14.8 \\
(1-55)\end{array}$ & $\begin{array}{c}26.6 \pm 15.3 \\
(2-55)\end{array}$ & $\begin{array}{c}26.6 \pm 14.4 \\
(1-53)\end{array}$ & 1.00 \\
\hline Able to rise from a chair independently without arm-support†, n (\%) & $70(37)$ & $32(35)$ & $38(38)$ & 0.68 \\
\hline Geriatric Depression Scale (0-15), mean \pm SD (range) $(\mathrm{n}=180)$ & $\begin{array}{c}4.4 \pm 3.2 \\
(0-14)\end{array}$ & $\begin{array}{c}4.6 \pm 3.4 \\
(0-14)\end{array}$ & $\begin{array}{c}4.2 \pm 2.9 \\
(0-14)\end{array}$ & 0.46 \\
\hline Body Mass Index, mean \pm SD (range) $(\mathrm{n}=189)$ & $\begin{array}{c}24.8 \pm 4.5 \\
(13.7-41.0)\end{array}$ & $\begin{array}{c}24.9 \pm 4.4 \\
(13.7-35.9)\end{array}$ & $\begin{array}{c}24.7 \pm 4.6 \\
(14.1-41.0)\end{array}$ & 0.79 \\
\hline Mini Nutritional Assessment (0-30), mean \pm SD (range) $(n=188)$ & $\begin{array}{l}20.5 \pm 3.7 \\
(5.5-27.5)\end{array}$ & $\begin{array}{l}20.4 \pm 3.9 \\
(10-27.5)\end{array}$ & $\begin{array}{l}20.6 \pm 3.6 \\
(5.5-26.5)\end{array}$ & 0.65 \\
\hline Health, self-perceived as better than age peers $\neq, n(\%)(n=189)$ & $77(41)$ & $30(33)$ & $47(48)$ & 0.04 \\
\hline
\end{tabular}


subtracted from the total number of observation days. A fall was defined as an event in which the participant unintentionally came to rest on the floor, regardless of whether or not an injury was sustained or what caused the fall. Thus, all falls were included in the study, including those resulting from, for instance, acute disease or an epileptic seizure. Falls were documented by the staff on report forms which included information about injuries, i.e., fractures, strains, cuts, bruising, abrasions, pain, and "unspecified physical discomfort", as well as whether the fall resulted in hospital treatment. This was a routine already existing within the facilities. To improve the reporting of falls further, the regular charts were reviewed. In order to observe a possible adverse effect of the intervention, falls were also recorded (in the same manner) during the 3-month intervention period.

\section{Baseline assessments}

The resident's registered nurse recorded diagnoses, clinical characteristics, and prescribed drugs. Most baseline assessments were performed by trained PTs. Hearing impairment was noted if participants could not hear a conversation at normal voice at a distance of 1 meter or if they used a hearing aid. Vision impairment was noted if participants, with or without glasses, could not read a word written in 5-mm capital letters at reading distance. Cognitive function was assessed by the MMSE. A licensed practical nurse or nurse's aide who knew the participant well was questioned about previous falls, as well as ADL by means of the Barthel Index $(38,39)$. Usual gait speed was measured by a 2.4-meter timed test (40), starting from a standing position. The mean of two attempts was chosen. Balance was assessed with the Berg Balance Scale $(41,42)$. Depressive symptoms were screened by the Geriatric Depression Scale (GDS-15) (43). A dietician assessed nutritional status by the Mini $\mathrm{Nu}$ tritional Assessment (MNA), which includes Body Mass In$\operatorname{dex}(\mathrm{BMI})\left(\mathrm{kg} / \mathrm{m}^{2}\right)(44)$. A specialist in geriatric medicine evaluated the documentation of diagnoses, drug treatments, assessments, and measurements for completion of final diagnoses.

The baseline characteristics of the 191 participants are listed in Table 1.

\section{Statistical methodology}

All analyses were based on the intention-to-treat principle, with data for all randomized participants remaining from when the study period started (intervention $n=191$, follow-up $n=183$ ) until they died, withdrew from the study, or completed the study period (Fig. 1). Baseline characteristics were compared between the two groups (exercise/control) by Student's $t$-test or the chi-square test.

A negative binominal regression was used to determine the difference between groups in fall rate by calculating incidence rate ratios (IRR) with 95\% CI. Negative binomial regression is a generalization of the Poisson regression which attempts to take into account the dependence of events by the same individual and is recommended for use in the evaluation of fall prevention (45). Logistic regression analysis was used to determine the difference between groups in proportion of participants who sustained at least one fall by calculating odds ratio (OR) with $95 \% \mathrm{CI}$. Both negative binominal and logistic regression analyses were adjusted for age, sex, and differences between groups $(p \leq 0.15)$ at baseline (visual impairment and selfperceived health).

To evaluate the effect between groups for participants with effect on physical function (measure of response to the intervention) and with higher attendance (measure of compliance), respectively, subgroup interaction analyses (not decided a priori) were carried out in the negative binominal and logistic regression analyses. The rationale for these subgroup analyses was to investigate further the effect of the exercise intervention by evaluating those participants with higher values in two aspects of the intervention - response and compliance - which were likely to explain a fall-prevention effect. For both exercise and control groups, the median (for all participants) of the difference in the Berg Balance Scale score (between post- and pre-intervention) was chosen to divide the participants into one group who responded and one group who did not. This meant that participants with an improvement in the Berg Balance Scale of 2 points or more during the 3-month intervention period were placed in the responding group. A variable of four categories was formed by study group (exercise/control) and effect on physical function (responding/not responding) and were added to the outcome analyses. Likewise, for attendance, the median was chosen to divide the sample of participants into one group with higher compliance (attended 23 or more of the 29 sessions) and one group with lower compliance. A variable of four categories was formed by study group (exercise/control) and attendance (higher compliance/lower compliance) and was added to the outcome analyses.

The results of the outcome analyses are presented without adjustments for randomization in clusters. The rationale for this was that cluster randomization was stratified in order to have both exercise and control groups in each facility, and, further, that there were few participants

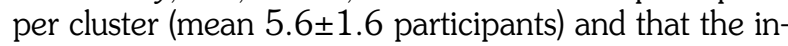
tervention was directed to individuals instead of to clusters (46). Nevertheless, the possibility of a cluster effect was examined in additional analyses by adjusting the outcome regression analyses for clustering (47).

Analyses were carried out with SPSS software, version 10.0 (SPSS Inc., Chicago, IL) and Stata software, version 9.1 (StataCorp, College Station, TX). All statistical tests were 2-tailed; $p<0.05$ was considered to indicate statistical significance. 


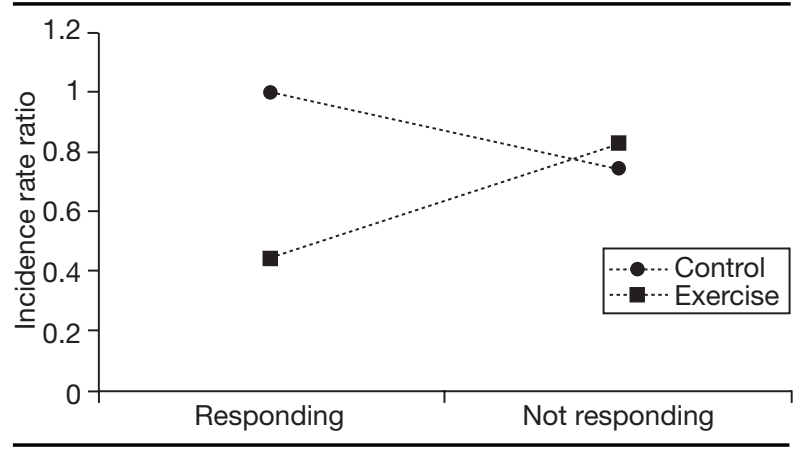

Fig. 2 - Subgroup interaction analysis, comparing effect of intervention (responding/not responding) and study groups (exercise/control). Responding= participants with improvement (between post- and pre-intervention) of 2 points or more in Berg Balance Scale during 3-month intervention period. "Control-Responding" is reference group. Incidence rate ratios were: "Exercise-Responding" 0.44 (95\% CI 0.21-0.91), "Control-Not responding" 0.75 (95\% CI 0.38-1.50), and "Exercise-Not responding" 0.83 (95\% CI 0.40-1.76).

\section{RESULTS}

During the 6-month follow-up period, 95 (52\%) of the 183 participants sustained one fall or more and 57 (31\%) participants fell twice or more. Falls per participant ranged from 0 to 26 . A total of 341 falls occurred during 29,978 observation days. The corresponding fall rate was 4.2 falls per person years (PY). One hundred and forty-five $(43 \%)$ of the falls resulted in an injury (64 in the exercise group, 81 in the control group), of which 10 resulted in a fracture (ex- ercise group four, control group six). Three falls resulted in a hip fracture (all in the control group) and 26 falls resulted in hospital treatment (exercise group 9, control group 17).

During the 3-month intervention period, 84 (44\%) of the 191 participants sustained one fall or more, 39 participants (43\%) in the exercise group and $45(45 \%)$ in the control group. Falls per participant ranged from 0 to 16 . A total of 193 falls occurred during 16,204 observation days. The corresponding fall rate was 4.4 falls per PY (exercise group 4.6 falls per PY, control group 4.2 falls per PY).

\section{Outcome analyses}

During the 6-month follow-up period, when all participants were compared, no statistically significant differences between the groups were found for fall rate (exercise group 3.6 falls per PY, control group 4.6 falls per PY) or proportion of participants sustaining a fall (exercise 53\%, control 51\%) (Table 2).

Among participants who responded, the exercise group had a lower fall rate than the control group (exercise group 2.7 falls per PY, control group 5.9 falls per PY), IRR (95\% CI) 0.44 (0.21-0.91), $p=0.03$ (Table 2, Fig. 2). In this subgroup, $42 \%$ of the participants in the exercise group fell, compared with $56 \%$ in the control group, OR (95\% CI) 0.50 (0.20-1.24), $p=0.13$ (Table 2). No significant difference was found between the groups among participants with higher compliance.

Outcome analyses adjusted for cluster randomization produced essentially the same results as unadjusted analyses (data not shown).

Table 2 - Outcome analyses of fall rate (falls per person years) and proportion of participants sustaining a fall, comparing all participants in exercise group with control group, as well as by additional subgroup interaction analyses.

\begin{tabular}{|c|c|c|c|c|c|c|}
\hline Group & Fall rate* & IRR $^{\dagger}(95 \% \mathrm{CI})$ & $p$ & $\begin{array}{l}\text { Participants with } \\
\text { any fall, n (\%) }\end{array}$ & $\mathrm{OR}^{\ddagger}(95 \% \mathrm{CI})$ & $\boldsymbol{p}$ \\
\hline Control activity $(n=96)$ & 4.6 & 1.00 , reference & & $49(51)$ & 1.00 , reference & \\
\hline Exercise $(n=87)$ & 3.6 & $0.82(0.49-1.39)$ & 0.46 & $46(53)$ & $0.95(0.52-1.74)$ & 0.86 \\
\hline \multicolumn{7}{|l|}{ Group and response to intervention $\S$} \\
\hline Control - responding $(n=39)$ & 5.9 & 1.00 , reference & & $22(56)$ & 1.00 , reference & \\
\hline Exercise - responding $(n=43)$ & 2.7 & $0.44(0.21-0.91)$ & 0.03 & $18(42)$ & $0.50(0.20-1.24)$ & 0.13 \\
\hline Control - not responding $(n=52)$ & 3.9 & $0.75(0.38-1.50)$ & 0.42 & $27(52)$ & $0.85(0.36-2.00)$ & 0.72 \\
\hline Exercise - not responding $(n=39)$ & 4.3 & $0.83(0.40-1.76)$ & 0.64 & $25(64)$ & $1.18(0.46-3.02)$ & 0.72 \\
\hline \multicolumn{7}{|c|}{ Group and compliance with intervention पा } \\
\hline Control - higher compliance $(n=50)$ & 4.4 & 1.00 , reference & & $28(56)$ & 1.00 , reference & \\
\hline Exercise - higher compliance $(n=43)$ & 3.3 & $0.77(0.38-1.56)$ & 0.46 & $23(53)$ & $0.89(0.38-2.06)$ & 0.78 \\
\hline Control - lower compliance $(n=46)$ & 4.8 & $1.29(0.62-2.68)$ & 0.50 & $21(46)$ & $0.65(0.28-1.51)$ & 0.32 \\
\hline Exercise - lower compliance $(n=44)$ & 4.0 & $1.12(0.54-2.34)$ & 0.76 & $23(52)$ & $0.66(0.28-1.58)$ & 0.35 \\
\hline \multicolumn{7}{|c|}{$\begin{array}{l}\text { *Falls per person years. }{ }^{\dagger} \mathrm{IRR}=\text { Incidence rate ratio according to negative binomial analyses adjusted for age, sex, and differences between groups }(\mathrm{p} \leq 0.15) \text { at } \\
\text { baseline (visual impairment and self-perceived health). }{ }^{\ddagger} \mathrm{OR}=\text { Oddd ratio }(95 \% \mathrm{CI}) \text { according to logistic regression analyses adjusted for age, sex and differences } \\
\text { between groups ( } \mathrm{p} \leq 0.15) \text { at baseline (visual impairment and self-perceived health). SResponding= participants with improvement (between post-and pre-intervention) } \\
\text { of } 2 \text { points or more in Berg Balance Scale during 3-month intervention period. Data for Berg Balance Scale were complete for } 173 \text { participants. }{ }^{9} H \text { Higher com- } \\
\text { pliance= participants who attended } 23 \text { or more of a total of } 29 \text { sessions. }\end{array}$} \\
\hline
\end{tabular}




\section{Additional analyses}

Analyses were carried out to identify baseline characteristics associated with a response to the exercise intervention. No significant differences were found in the exercise group between participants who responded and those who did not, in age, sex, Mini-Mental State Examination, Barthel ADL index, Berg Balance Scale or Geriatric Depression Scale (data not shown).

Among participants who responded during the 3-month intervention period, the extent of balance improvement did not significantly differ between the exercise and control groups (mean \pm SD $7.2 \pm 4.2$ vs $6.5 \pm 3.5, p=0.40$ )

Nineteen drop-outs occurred during the study due to deaths, of which two occurred during the intervention period (Fig. 1). The relation between cause of death and the study (intervention and test procedure) were evaluated by a specialist in geriatric medicine. In one case, association with the study could not definitely be excluded. This participant died suddenly of an acute ruptured aortic-abdominal aneurysm one week after the follow-up tests of the 3-month exercise intervention had been performed.

\section{DISCUSSION}

Among older people living in residential care facilities, a high-intensity functional exercise program did not overall significantly reduce either fall rate or proportion of participants who sustained a fall, compared with a control activity. In a subgroup interaction analysis among those who responded, a significant reduction in fall rate was seen in the exercise group, compared with the control group. Furthermore, among those who responded, a $50 \%$ non-significant reduction in the proportion of participants who sustained a fall was seen in the exercise group. However, the results of these subgroup analyses, which were not decided a priori, should be interpreted with caution.

The absence of a general fall-prevention effect through exercise as a single intervention in this study matches most other exercise studies in various types of residential care facilities $(29,30)$. To our knowledge, only one study has shown a reduction in falls in this kind of setting (32). In that study, which had a small sample size, residents with a diagnosis of dementia were excluded, and participants' balance function was considerably better than in the present study (31). However, among people living in the community or in retirement villages, several studies have shown positive fall-prevention effects resulting from exercise as a single intervention (24-28). Thus, it seems less likely that exercise as a single fall intervention would be successful in older people living in residential care facilities, compared with older people living in the community. One explanation for this difference in effect may be the broad spectrum of predisposing and precipitating factors for falls in older people living in residential care facilities (9). This indicates the advantages, in this setting, of combining exercise with other fall-prevention interventions - an approach which has been shown to be successful in two studies $(16,19)$.

An interesting finding from the subgroup interaction analyses was that, among those participants who improved their balance during the intervention period, the exercise group had a significantly lower fall rate than the control group. This highlights the possible lack of direct association between improvements assessed by balance measures and improved control in real-life balance demands, i.e., situations that cause a fall risk (48). Comparisons with individuals who had both improved their balance and received control activity strengthen the interpretation that the fall-prevention effect was obtained by an interaction between training program and improvements in balance. The functional weight-bearing exercise program, which includes everyday tasks such as standing up from a chair or climbing stairs, may have created favorable conditions for transferring improvements in physical function to safer performance of daily living activities. Participants may, for example, have perceived their own capabilities and learned strategies for avoiding falls in physical tasks that fully challenged their stability limits. The fall-prevention effect for the entire exercise group might have improved if task-specific training carried out in each participant's everyday environment had been added to the exercise program, especially as many of the participants had cognitive impairments which may have obstructed transferring the performance of a task in a supervised exercise session to its performance in everyday life. Learning more about specific responses to exercise and other fall interventions with regard to the varying characteristics of participants is important, especially concerning people with a diagnosis of dementia, one group of older people for whom no fall intervention has proved successful (49).

The literature revealed no reliable cut-off score for the Berg Balance Scale that indicates a significant improvement over time on an individual level. The median score of change over time was used, instead, to divide participants into one group who responded and one who did not. To our surprise, almost as large a proportion of participants in the control group (39 out of $91,43 \%$ ) as in the exercise group (43 out of $82,52 \%$ ) were categorized as responding according to this definition. Instead, a decline in physical function over time would have been expected in a control group including older people with multiple diseases and impairments in physical and cognitive functions. One explanation is that the control activity program had an effect on physical function in this sedentary group, e.g., through the impact of social stimulation, meaningful activities, or transferring to another location in the facility.

A major limitation of this study was low statistical power. The power was slightly over $50 \%$ to show a $20 \%$ significant reduction in falls (two-sided significance of 0.05 with Poisson regression). Despite this, evaluation of falls seemed important in addition to evaluation of phys- 
ical function outcomes (for which the study had $80 \%$ power) (33). However, more participants or a longer follow-up period would certainly have been preferable in evaluating falls. In addition, the exclusion of those with an MMSE score of less than 10 and those who needed help from more than one person in standing up from a chair limits external validity.

There were few differences between groups at baseline that had to be adjusted for in the outcome analyses, although the intervention was randomized in clusters. Factors contributing to this may have been that the randomization included many clusters and was performed after the inclusion of participants, which eliminated the risk of selection bias. Probably, not all falls were recorded. However, the high fall rate in the present study and the use of two ways of collecting data on falls (staff reports and review of regular charts) indicate that the recordings included most falls.

The main clinical implication of this study is that the results strengthen the belief that high-intensity functional exercise programs are an important part of fall-preventive interventions among older people in residential care facilities. However, future studies, larger than the present one, are needed to determine whether these results can be replicated or improved. In addition, it seems important to investigate further what characterizes people who are likely to respond to the exercise intervention.

\section{CONCLUSIONS}

This study could not prove that a high-intensity functional exercise program among older people who are dependent in ADL and living in residential care facilities had a general fall-prevention effect. However, there may be a fall-prevention effect among residents who improve their balance through the exercise intervention.

\section{ACKNOWLEDGEMENTS}

The authors acknowledge and thank Håkan Littbrand, PT, and Nina Lindelö, PT, for the development of the HIFE Program and for their helpful comments on drafts of this paper; Andreas Marklund, PT, and Stefan Sehlstedt, PT, for their contribution to the collection of fall records; and Hans Stenlund for most important statistical advice. We also wish to express our gratitude to the Social Authorities of the municipality of Umeå, the participants, and the staff at the facilities for their cooperation and participation.

This work was supported by grants from the Ragnhild and Einar Lundström's Memorial Foundation, Dementia Fund, Vårdal Foundation, Gun and Bertil Stohne Foundation, Erik and Anne-Marie Detlof's Foundation, Borgerskapet in Umeå Research Foundation, Swedish Research Council K2002-27VP-14165-02B, K2002-27VX-1417202B, K2005-27VX-15357-01A, and Swedish Council for Working Life and Social Research.

\section{REFERENCES}

1. Tinetti ME, Speechley M, Ginter SF. Risk factors for falls among elderly persons living in the community. N Engl J Med 1988; 319: 1701-7.

2. Luukinen $\mathrm{H}$, Koski K, Hiltunen L, Kivelä SL. Incidence rate of falls in an aged population in northern Finland. J Clin Epidemiol 1994; 47: 843-50.
3. O'Loughlin JL, Robitaille Y, Boivin JF, Suissa S. Incidence of and risk factors for falls and injurious falls among the communitydwelling elderly. Am J Epidemiol 1993; 137: 342-54.

4. Nevitt MC, Cummings SR, Kidd S, Black D. Risk factors for recurrent nonsyncopal falls. A prospective study. JAMA 1989; 261: 2663-8.

5. Sattin RW, Mullins RJ. Geriatric trauma: the continuing epidemic. J Am Geriatr Soc 2002; 50: 394-5.

6. Vellas BJ, Wayne SJ, Romero LJ, Baumgartner RN, Garry PJ. Fear of falling and restriction of mobility in elderly fallers. Age Ageing 1997; 26: 189-93.

7. Cumming RG, Salkeld G, Thomas M, Szonyi G. Prospective study of the impact of fear of falling on activities of daily living, SF-36 scores, and nursing home admission. J Gerontol A Biol Sci Med Sci 2000; 55: M299-305.

8. Delbaere K, Crombez G, Vanderstraeten G, Willems T, Cambier D. Fear-related avoidance of activities, falls and physical frailty. A prospective community-based cohort study. Age Ageing 2004; 33: 368-73.

9. Kallin K, Jensen J, Lundin-Olsson L, Nyberg L, Gustafson Y. Why the elderly fall in residential care facilities, and suggested remedies. J Fam Pract 2004; 53: 41-52.

10. Luukinen H, Koski K, Honkanen R, Kivelä SL. Incidence of injurycausing falls among older adults by place of residence: a population-based study. J Am Geriatr Soc 1995; 43: 871-6.

11. Masud T, Morris RO. Epidemiology of falls. Age Ageing 2001; 30 (Suppl 4): 3-7.

12. Tinetti ME. Clinical practice. Preventing falls in elderly persons. N Engl J Med 2003; 348: 42-9.

13. Chang JT, Morton SC, Rubenstein LZ, et al. Interventions for the prevention of falls in older adults: systematic review and meta-analysis of randomised clinical trials. BMJ 2004; 328: 680-3.

14. Gillespie LD, Gillespie WJ, Robertson MC, Lamb SE, Cumming RG, Rowe $\mathrm{BH}$. Interventions for preventing falls in elderly people. Cochrane Database Syst Rev 2003: CD000340.

15. Rubenstein LZ, Robbins AS, Josephson KR, Schulman BL, Osterweil $\mathrm{D}$. The value of assessing falls in an elderly population. A randomized clinical trial. Ann Intern Med 1990; 113: 308-16.

16. Becker $\mathrm{C}$, Kron M, Lindemann U, et al. Effectiveness of a multifaceted intervention on falls in nursing home residents. J Am Geriatr Soc 2003; 51: 306-13.

17. Kerse N, Butler M, Robinson E, Todd M. Fall prevention in residential care: a cluster, randomized, controlled trial. J Am Geriatr Soc 2004; 52: 524-31.

18. Dyer CA, Taylor GJ, Reed M, Robertson DR, Harrington R. Falls prevention in residential care homes: a randomised controlled trial. Age Ageing 2004; 33: 596-602.

19. Jensen J, Lundin-Olsson L, Nyberg L, Gustafson Y. Fall and injury prevention in older people living in residential care facilities. A cluster randomized trial. Ann Intern Med 2002; 136: 733-41.

20. McMurdo ME, Millar AM, Daly F. A randomized controlled trial of fall prevention strategies in old peoples' homes. Gerontology 2000; 46: 83-7.

21. Schnelle JF, Kapur K, Alessi C, et al. Does an exercise and incontinence intervention save healthcare costs in a nursing home population? J Am Geriatr Soc 2003; 51: 161-8.

22. Latham NK, Bennett DA, Stretton CM, Anderson CS. Systematic review of progressive resistance strength training in older adults. J Gerontol A Biol Sci Med Sci 2004; 59: 48-61.

23. Day L, Fildes B, Gordon I, Fitzharris M, Flamer H, Lord S. Randomised factorial trial of falls prevention among older people living in their own homes. BMJ 2002; 325: 128-31. 
24. Robertson MC, Devlin N, Gardner MM, Campbell AJ. Effectiveness and economic evaluation of a nurse delivered home exercise programme to prevent falls. 1: Randomised controlled trial. BMJ 2001; 322: 697-701.

25. Campbell AJ, Robertson MC, Gardner MM, Norton RN, Tilyard MW, Buchner DM. Randomised controlled trial of a general practice programme of home based exercise to prevent falls in elderly women. BMJ 1997; 315: 1065-9.

26. Skelton D, Dinan S, Campbell M, Rutherford O. Tailored group exercise (Falls Management Exercise - FaME) reduces falls in community-dwelling older frequent fallers (an RCT). Age Ageing 2005; 34: 636-9.

27. Barnett A, Smith B, Lord SR, Williams M, Baumand A. Community-based group exercise improves balance and reduces falls in at-risk older people: a randomised controlled trial. Age Ageing 2003; 32: 407-14.

28. Lord SR, Castell S, Corcoran J, et al. The effect of group exercise on physical functioning and falls in frail older people living in retirement villages: a randomized, controlled trial. J Am Geriatr Soc 2003; 51: 1685-92.

29. Mulrow CD, Gerety MB, Kanten D, et al. A randomized trial of physical rehabilitation for very frail nursing home residents. JAMA 1994; 271: 519-24.

30. Nowalk MP, Prendergast JM, Bayles CM, D'Amico FJ, Colvin GC. A randomized trial of exercise programs among older individuals living in two long-term care facilities: the FallsFREE program. J Am Geriatr Soc 2001; 49: 859-65.

31. Sihvonen SE, Sipilä S, Era PA. Changes in postural balance in frail elderly women during a 4-week visual feedback training: a randomized controlled trial. Gerontology 2004; 50: 87-95.

32. Sihvonen S, Sipilä S, Taskinen S, Era P. Fall incidence in frail older women after individualized visual feedback-based balance training. Gerontology 2004; 50: 411-6.

33. Rosendahl $\mathrm{E}$, Lindelöf $\mathrm{N}$, Littbrand $\mathrm{H}$, et al. A high-intensity functional exercise program and a protein-enriched energy supplement for older persons dependent in ADL: a randomised controlled trial. Aust J Physiother 2006; 52: 105-13.

34. Katz S, Ford AB, Moskowitz RW, Jackson BA, Jaffe MW. Studies of Illness in the Aged. The index of ADL: a standardized measure of biological and psychosocial function. JAMA 1963; 185: 914-9.

35. Folstein MF, Folstein SE, McHugh PR. Mini-Mental State. A practical method for grading the cognitive state of the patient for the clinician. J Psychiatr Res 1975; 12: 189-98.

36. Littbrand H, Rosendahl E, Lindelöf N, Lundin-Olsson L, Gustafson Y, Nyberg L. A high-intensity functional weight-bearing exercise program for older people dependent in activities of daily living and living in residential care facilities: evaluation of the applicability with focus on cognitive function. Phys Ther 2006; 86: 489-98.

37. DeLorme TL. Restoration of muscle power by heavy-resistance exercises. J Bone Joint Surg 1945; 27: 645-67.

38. Mahoney FI, Barthel DW. Functional evaluation: the Barthel Index. Maryland State Med J 1965; 14: 61-5.

39. Wade DT. Measurement in neurological rehabilitation. Oxford: Oxford University Press, 1992.

40. Guralnik JM, Simonsick EM, Ferrucci L, et al. A short physical performance battery assessing lower extremity function: association with self-reported disability and prediction of mortality and nursing home admission. J Gerontol 1994; 49: M85-94.

41. Berg KO, Wood-Dauphinee SL, Williams JI, Maki B. Measuring balance in the elderly: validation of an instrument. Can J Public Health 1992; 83 (Suppl 2): S7-11.

42. Berg K, Wood-Dauphinee S, Williams JI. The Balance Scale: reliability assessment with elderly residents and patients with an acute stroke. Scand J Rehabil Med 1995; 27: 27-36.

43. Sheikh JI, Yesavage JA. Geriatric Depression Scale (GDS): recent evidence and development of a shorter version. Clin Gerontol 1986; 5: 165-72.

44. Guigoz Y, Vellas B, Garry PJ. Mini Nutritional Assessment: a practical assessment tool for grading the nutritional state of elderly patients. Facts and Research in Gerontology 1994; (Suppl 2): 15-59.

45. Robertson MC, Campbell AJ, Herbison P. Statistical analysis of efficacy in falls prevention trials. J Gerontol A Biol Sci Med Sci 2005; 60: 530-4.

46. Kerry SM, Bland JM. The intracluster correlation coefficient in cluster randomisation. BMJ 1998; 316: 1455.

47. Campbell MK, Elbourne DR, Altman DG. CONSORT statement: extension to cluster randomised trials. BMJ 2004; 328: 702-8.

48. Lavery LL, Studenski SA. Tai chi, falls, and the heritage of JAGS. J Am Geriatr Soc 2003; 51: 1804-5.

49. Shaw FE, Bond J, Richardson DA, et al. Multifactorial intervention after a fall in older people with cognitive impairment and dementia presenting to the accident and emergency department: randomised controlled trial. BMJ 2003; 326: 73-8. 